This document is the accepted manuscript version of the following article:

Wheeler, J. M., Armstrong, D. E. J., Heinz, W., \& Schwaiger, R. (2015). High temperature nanoindentation: the state of the art and future challenges. Current opinion in Solid State and Materials Science, 19(6), 354-366. https: //doi.org/10.1016/j.cossms. 2015.02.002

\title{
High TEMPERATURE NANOINDENTATION: The State of THE ART AND Future Challenges
}

\author{
J.M. Wheeler ${ }^{1}$, D.E.J. Armstrong ${ }^{2}$, W. Heinz ${ }^{3}$, R. Schwaiger ${ }^{4}$ \\ ${ }^{1}$ Empa, Swiss Federal Laboratories for Materials Science and Technology, \\ Laboratory for Mechanics of Materials and Nanostructures \\ Feuerwerkerstrasse 39, CH-3602 Thun, Switzerland \\ e-mail: Jeff.Wheeler@mat.ethz.ch \\ ${ }^{2}$ University of Oxford, Department of Materials, \\ Parks Road, OX1 3PH Oxford, United Kingdom \\ ${ }^{3}$ Kompetenzzentrum Automobil- und Industrie-Elektronik GmbH, \\ Europastraße 8, A-9524 Villach, Austria \\ ${ }^{4}$ Karlsruhe Institute of Technology (KIT), Institute for Applied Materials (IAM), \\ P.O. Box 3640, D-76021 Karlsruhe, Germany
}

\begin{abstract}
Nanoindentation measurement capabilities at elevated temperatures have developed considerably over the last two decades. Commercially available systems can now perform stable indentation testing at temperatures up to $\sim 800^{\circ} \mathrm{C}$ with thermal drift levels similar to those present at room temperature. The thermal management and measurement techniques necessary to achieve this are discussed here, with particular emphasis on systems featuring independent heating of both the indenter and the sample. To enable measurements at temperatures where oxidation of the indenter and/or sample are a concern, vacuum nanoindentation techniques have also been developed. A natural extension of testing in vacuo is elevated temperature nanoindentation in situ in the scanning electron microscope, and the additional requirements for and benefits of this are discussed. Finally, several new emerging testing techniques are introduced: thermal cycling/fatigue, interfacial thermal resistance measurement and small scale transient plasticity measurements.
\end{abstract}

Keywords: nanoindentation; microcompression; high temperature; in situ

\section{Introduction}

Nanoindentation testing is currently one of the most popular techniques for mechanical characterization. Its great success is due in part to the simplicity of the sample requirements: a clean, flat surface. A flat, damage-free surface is not always easy to achieve [1], however this simple geometry provides significant advantages over conventionally scaled tension or compression tests which require carefully machined samples and much larger quantities of material. A large part of the popularity of modern nanoindentation systems is undoubtedly due to their ability to perform automated data collection and analysis: a sample is inserted, the desired tests are specified, and the user collects their statistically evaluated results a short time later. This breakthrough capability was facilitated by the Oliver and Pharr analysis [2], which allowed mechanical properties to be directly extracted from the load-displacement curves without additional characterization of the residual impression.

As with all mechanical properties, hardness and elastic modulus values extracted by nanoindentation are dependent on temperature. This makes variable temperature nanoindentation relevant to industrial applications for understanding materials behavior at 
service temperatures and conditions. Scientifically, variable temperature nanoindentation is interesting, because the small scales involved allow much tighter control and/or selection of microstructural features of interest which are interrogated by the technique. This allows the kinetic aspects of fundamental materials physics to be investigated in new ways and in materials where investigation using conventional methods was not feasible.

Furthermore, by combining the load and displacement resolution of nanoindentation systems with small-scale sample manufacturing techniques - such as focused ion beam machining or lithography - a wide range of micro-scale compression, tension, shear, and fracture geometries become available. This allows specific properties of new materials, e.g. the fracture toughness of a thin film multilayer at elevated temperature, to be investigated on the small scale to determine how to improve them prior to scaling up to bulk production.

High temperature nanoindentation has developed significantly over the past two decades. During this period, several authors have reviewed the state of the art at different points in time [3-11]. Typically each of these reviews has focused largely on one particular manufacturer's nanoindentation system and its high temperature capabilities. However, in this article, the state of the art of the nanoindentation systems capable of testing at high temperatures will be discussed from a general perspective by academic users of several different commercial systems. The major design elements featured in the commercially available systems are described in relation to their high temperature functionality. A significant portion of this paper is dedicated to techniques for identifying the sources of thermal drift, for eliminating thermal drift (a displacement measurement error resulting from thermal expansion) from measurements, and for correcting any small residual drift remaining. In order to reach the highest temperatures, vacuum techniques are required in most cases, and an overview of the considerations for this is provided. A logical extension of vacuum nanoindentation is in situ nanoindentation in the scanning electron microscope; this combines the benefits of vacuum nanoindentation with the observational and positioning capabilities of in situ testing. Several emerging applications of high temperature nanoindentation are briefly introduced: rapid thermal cycling of thin films, interfacial thermal resistance measurement, and transient plasticity measurements. A summary of the progress in developing high temperature nanoindentation techniques and future challenges are discussed.

\section{Technical Development of Nanoindentation Systems}

The progress made in developing high temperature indentation systems over the last two decades is schematically summarized in Figure 1. Most initial efforts to perform nanoindentation at elevated temperatures involved custom setups with only minor modifications to the conventional versions: a simple heater for the sample [12] or the changing the thermostat of the room [13]. One significant exception to this is the High Temperature Mechanical Properties Microprobe made by Lucas and Oliver in 1994 [14] based on the electromagnetic actuator system which has been sold under the labels of NanoInstruments, Inc., MTS Systems Corporation, Agilent Technologies, Inc., and now Keysight Technologies, Inc. and Nanomechanics, Inc. (NMI). This system featured a temperature range of $-100{ }^{\circ} \mathrm{C}$ to $75^{\circ} \mathrm{C}$ using independent indenter and sample heating in an ultra-high vacuum (UHV) chamber with liquid nitrogen cooling on both sides, achieving capabilities which wouldn't be exceeded or matched until recently. However, the manufacturing cost and difficulty of using this system precluded its commercialization and widespread adoption.

In 1997, Syed Asif and Pethica [15] used air-cooled Peltier elements on both indenter and sample sides to perform stable testing at slightly colder and warmer temperatures. Smith and Zheng [16] introduced the MicroMaterials Ltd. (MML) NanoTest system in 2000 using independent resistive heaters and control thermocouples for both indenter and sample with a horizontal pendulum that allows convection to vertically remove heat from the sensor region, 
which was additionally protected by a heat shield. This system allowed testing at elevated temperatures up to $400-500{ }^{\circ} \mathrm{C}$ with low thermal drifts due to the temperature matching of the indenter and sample possible due to the independent heaters. Higher temperatures were prohibited by oxidation of the diamond indenter [17].

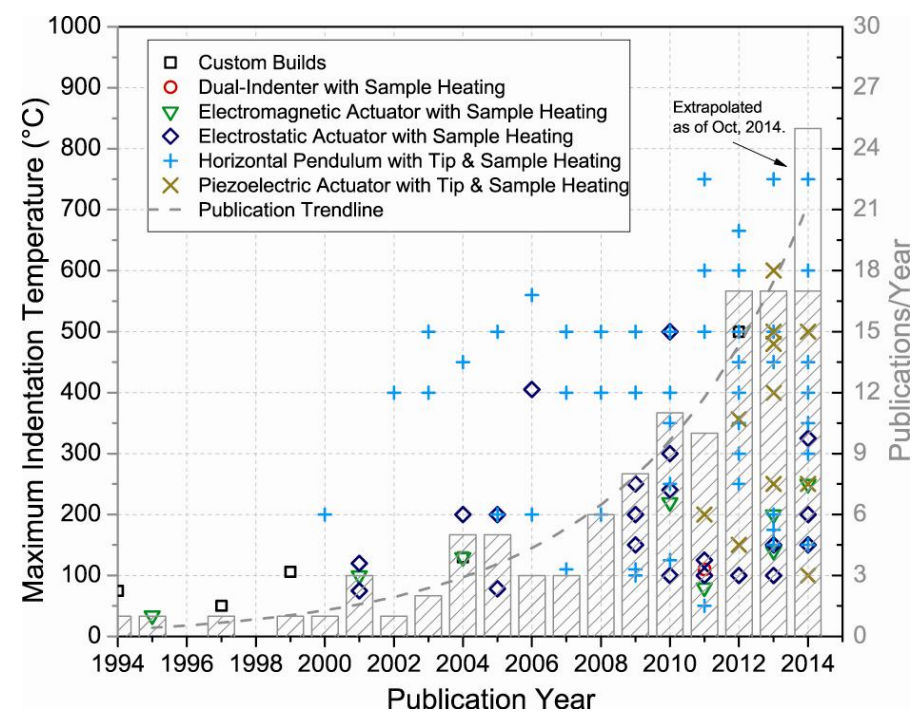

Figure 1: Maximum published indentation temperatures for various system configurations and publications per year in recent years [18].

This remained the most complicated thermal management system available until Schuh et al. [4] described a Hysitron system in 2006 which featured water cooling and heat shielding for an indenter mounted on a ceramic shaft and sample heating mounted on a water-cooled stage. However, the lack of indenter heating in this system prevented temperature matching, so that thermal drift was still observed to increase with increasing test temperature despite the extensive thermal management efforts. Despite this, this system was able to perform -eontactmode imaging" [4], which uses the indenter tip to perform scanning probe microscopy (SPM) with a very low force to measure surface topology.

During this period, atomic force microscopy (AFM) [19] was also developed for variable temperature characterization [20-24]. The efforts in this direction largely centered on generating smaller, more efficient heating elements using microfabrication techniques to produce isolated, suspended heating element platforms. This was possible due to the small scan areas and negligible stiffness requirements of AFM due to the small forces and extremely small contacts involved. By reducing the thermal mass of the heating element, very fast heating and cooling times were enabled, which also reduces the effect of heating on the sensors involved. Similarly to nanoindentation, vacuum, controlled atmosphere and cryogenic stages for AFM were also developed [25-27].

A new revision of the Hysitron system was revealed in 2010 [6], which featured an indenter shaft made of low coefficient of thermal expansion (CTE) ceramic and a controlled atmosphere chamber allowing operation in primary vacuum and inert gas atmosphere. This reduced, but did not eliminate, thermal drift, and oxidation of the indenter was still observed. A new version of the Hysitron system featuring a clamshell heater design, where the indenter is inserted into a furnace with heaters surrounding it in an atmosphere of shrouding gas, is now available, but no independent publications on this system were available for review as of the time of writing.

In 2010, CSM Instruments SA (Now Anton Paar) introduced a system featuring dual indenters to provide active surface referencing to eliminate thermal drift and frame compliance [28], which allowed low drift levels at temperatures up to $110^{\circ} \mathrm{C}$. In the following year, Wheeler et al. [29] described a modified Alemnis system with indenter and

$$
p-3-
$$


sample heating in situ in the scanning electron microscope. Subsequent publications $[9,30]$ revealed further modifications, such as incorporating a water-cooled copper baseplate to the frame and a cooled copper braid to protect the load cell.
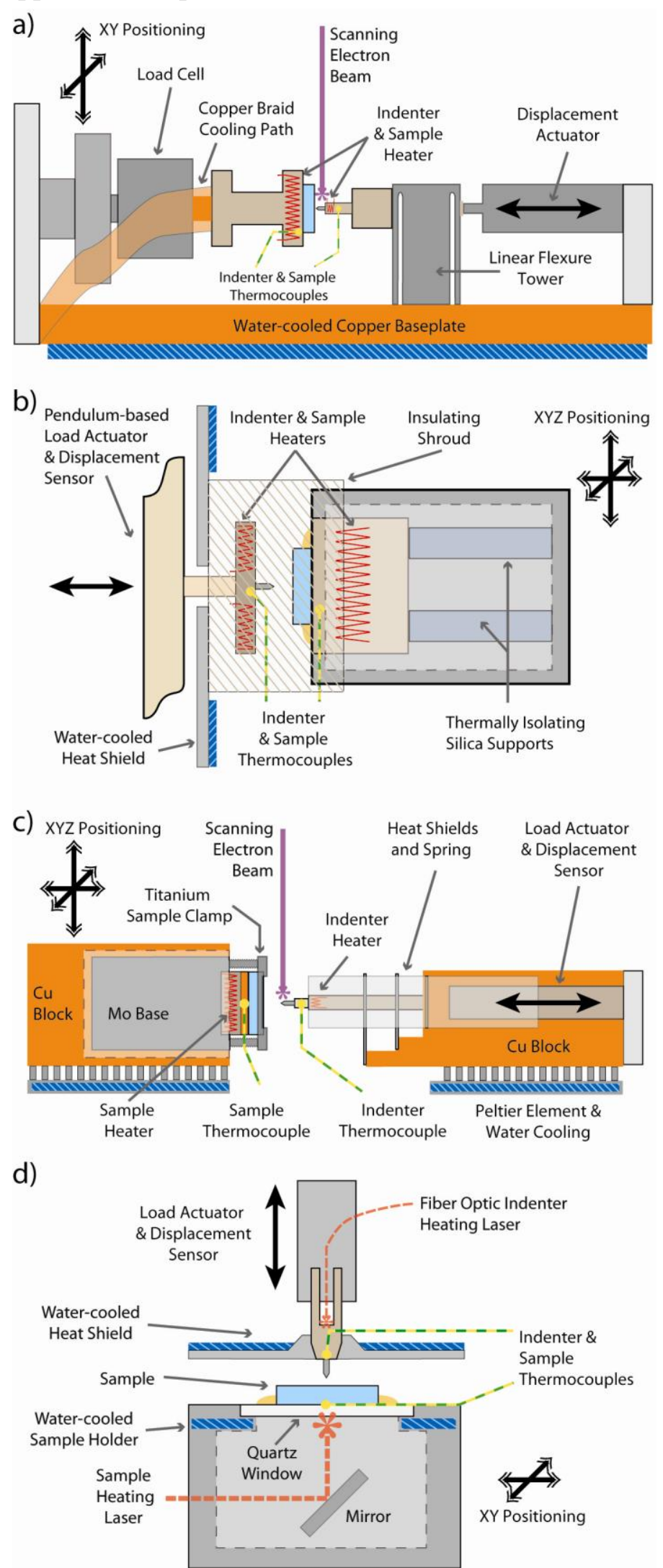

Figure 2: Schematics of the different heating arrangements commercially available from a) Alemnis AG, b) MicroMaterials Ltd., c) Nanomechanics Inc., d) and SURFACE GmbH laser heating for a Keysight system.

$$
p-4-
$$


In 2011, sapphire and cubic boron nitride indenters were implemented on a MicroMaterials system with a water-cooled heat shield, allowing temperatures above the oxidation onset temperature of diamond. The following year, high vacuum techniques were implemented [8] on another MML system, allowing use of diamond indenters at temperatures $>400{ }^{\circ} \mathrm{C}$ without oxidation.

The current state of the art for the four indentation systems capable of low thermal drift, high temperature indentation is shown schematically in Figure 2. A key feature of all of these systems is the independent heating of both the indenter and sample. This is considered to be essential for reasons which will be elaborated on in later sections. Figure $2 \mathrm{a}$ depicts the Alemnis system as described in the preceding paragraphs, and Figure $2 \mathrm{~b}$ illustrates the heating arrangement in the MML NanoXtreme system. Additional modifications in this system include a commercial high vacuum chamber, a water-cooled heat shield, and low CTE ceramic spacers in the sample heater.

The Nanomechanics, Inc. (NMI) elevated temperature, in situ nanoindentation system (Figure 2c) features a modular voice coil force actuator and displacement sensor which can be used either in an on-stage (cradle) or chamber-mounted configuration. For operation at high temperatures (up to $600{ }^{\circ} \mathrm{C}$ ), this system also features independent indenter and sample heating. However, this system also uniquely features active cooling through water and Peltier elements to achieve controlled cooling rates.

Figure 2d describes a laser-based heating arrangement from SURFACE systems + technology $\mathrm{GmbH} \& \mathrm{Co}$. KG implemented inside a Keysight G200 nanoindentation system. The system uses a $40 \mathrm{~W}$ laser for heating the sample, which is mounted using a specialized cement that absorbs the radiative heating from the laser. Temperature measuring is realized under the sample in a notch of the quartz holder. A second $4 \mathrm{~W}$ laser is used to heat the indenter tip via an optical fiber, which transmits the heat to a ceramic indenter holder. Both the indenter and sample also feature water cooling.

\section{Thermal Drift and Thermal Gradient Management}

\subsection{Defining Thermal Drift}

Thermal drift is a time-dependent error in displacement measurement during nanoindentation which arises from thermal expansion occurring somewhere within the system. This manifests as an additional displacement superimposed over the measured or applied displacement during testing. Due to the nanometer length scales involved in measuring displacement during nanoindentation, temperature variations within various system components of less than a degree Celsius can cause significant thermal drift. Thermal drift can be split into two separate contributions: frame drift and contact drift. Knowing which contribution(s) is/are causing thermal drift in the measurement is important, since it allows the user to take the appropriate steps to counter that specific source of error.

Frame drift is thermal drift which occurs due to temperature variations in the nanoindentation system's frame, away from the contact. This occurs at ambient conditions, due to atmospheric temperature variations, and is generally mitigable for moderate duration indentations ( $<1$ hour) using a sealed cabinet or enclosure with a stabilization period. Longer duration testing may require special procedures such as those discussed later. At elevated temperatures, frame drift arises due to thermal gradients between the heated components and the cooled or passive components. In both cases, this drift will decrease over time as the thermal gradients are established or eliminated and thermal expansion ceases. This is generally termed the stabilization period. The length of this stabilization period is generally on the order of an hour, but this can vary greatly between different systems depending on the change in temperature, the size of the system, the thermal conductivity of its components, and the power of the water-cooling system. If the time scale of an indentation is small compared to the stabilization period, then frame drift is normally small and linear as a function of time.

$$
p-5-
$$


As frame drift is independent of the contact, the magnitude of the thermal drift will be the same whether it is measured by a hold period prior to indentation or during a hold period during unloading.

Contact drift is thermal drift which occurs due to heat flow between the indenter and the sample at the contact due to a difference in temperature between them. At ambient temperatures, this is negligible. At elevated temperatures, however, any difference between the indenter and sample becomes magnified and increasingly significant. The amount of heat flow through the contact depends on several factors [9]: contact area, materials properties, pressure, and thermal gradient. Because these factors vary during indentation, contact drift has been observed to be non-linear with time [7,9]. Since contact drift only occurs when the indenter and sample are in contact, it will not be apparent during a hold period prior to indentation. During a hold period during unloading, however, the apparent thermal drift will be the sum of the frame and the contact drift.

In order to minimize or eliminate thermal drift from load-displacement measurements at elevated temperatures, it is essential that both types of drift are minimized. This occurs when the thermal gradients within the system frame are stable and contained and when the temperatures of the indenter and the sample are precisely matched. Stabilization of the indenter frame simply requires waiting a certain period of time; the length of which is dependent on how rapidly the system stabilizes and the magnitude of the temperature change. Matching the indenter and sample temperatures requires additional techniques.

\subsection{Indenter and Sample Temperature Matching}

Matching the indenter and sample temperatures has been repeatedly shown to be essential to eliminating drift at high temperatures. In systems where only the sample is heated, contact thermal drift will increase with temperature $[6,31]$ due to the increasing thermal gradient between the sample and the indenter. Passively heating the indenter by leaving the tip in contact for a stabilization period can reduce the temperature gradient between the tip and the sample, but thermal drift will still increase with temperature. Also, a passively heated indenter will never completely reach the same temperature as the sample [9], since it functions as a local heat sink. This creates increasing amounts of temperature uncertainty at the contact at elevated temperatures. Independently heating and monitoring the temperature of both the indenter and the sample allows this to be eliminated.

If both the indenter and the sample are heated independently, contact thermal drift is a function of how closely the indenter and sample temperatures are matched. Two methods for tuning the indenter and sample temperature have been demonstrated in the literature: using thermal drift to align temperature [7, 32] and using indenter thermocouple temperature measurements to directly observe if the indenter loses or gains heat during contact $[9,33]$. In the first method (Figure 3a), several indentations are performed where the indenter temperature is varied relative to the sample temperature, and thermal drift is measured as a function of indenter temperature to find a minimum. This assumes that the temperatures are matched when drift is at a minimum, so frame drift must be eliminated prior to the use of this method.

In the second method (Figure 3b), the tuning is performed using temperature measurements made with the indenter thermocouple. This is accomplished by setting the indenter heater to constant heating power prior to indentation, then recording the indenter temperature variation during contact. If the indenter and sample are matched, the temperature will not significantly vary during contact. If the temperature is observed to change, then the indenter setpoint temperature is adjusted in the opposite direction of the shift. The inset of Figure $3 \mathrm{~b}$ illustrates how tuning can be expedited by determining the trend of the maximum temperature shift versus the indenter setpoint temperature to identify the matching temperature where there is no temperature shift during contact.

$$
p-6-
$$


An advantage of the second method is that tuning can be performed while the thermal gradients within the system frame are still stabilizing. This saves considerable time during the setup of each experiment. Furthermore, the direction of the temperature shift directly indicates whether the indenter is colder or hotter, whereas the displacement drift direction is less reliably indicative. Both of these factors make temperature matching using thermocouples significantly faster than displacement drift tuning.
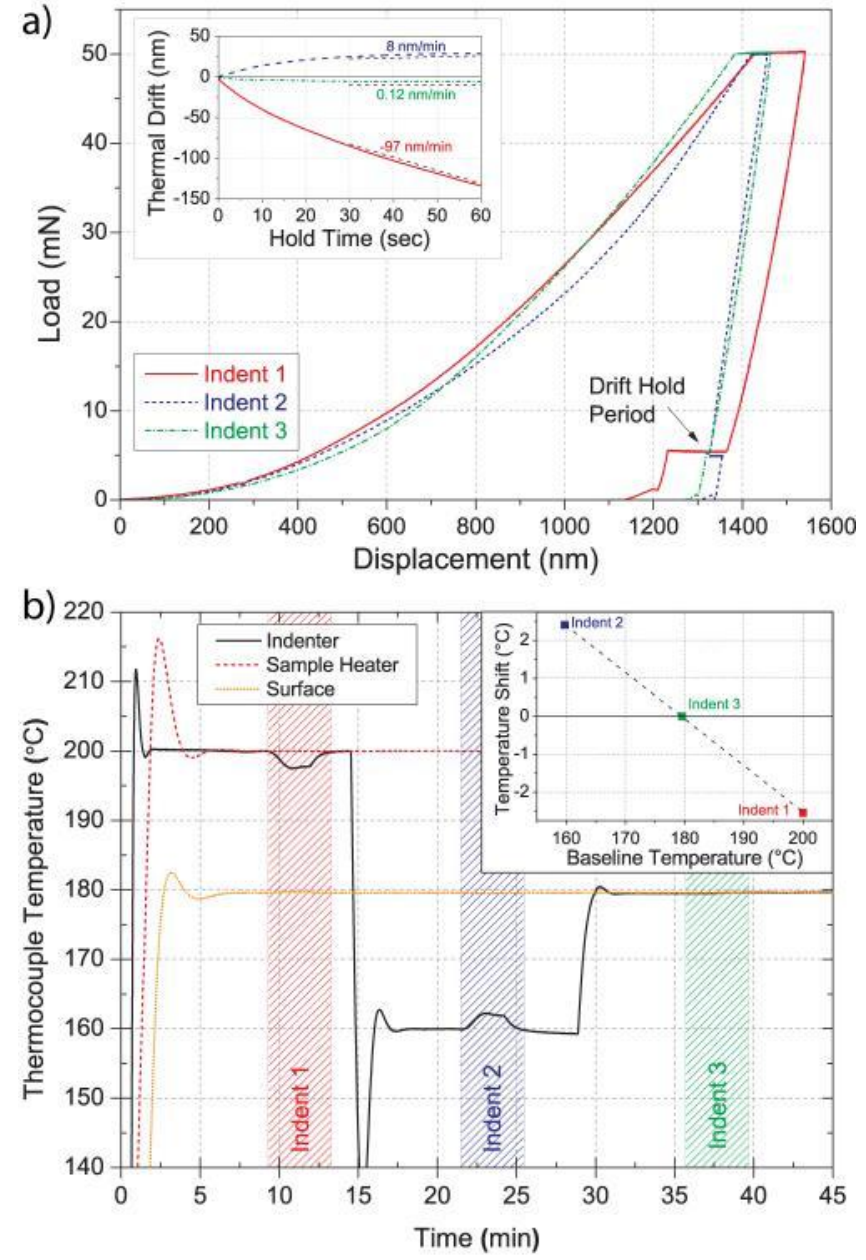

Figure 3: Indenter-sample temperature matching procedures using a) thermal displacement drift and b) indenter temperature shift magnitudes to determine the isothermal contact temperature.

Both of these methods can successfully be used to match the indenter and sample temperatures at the contact. However, the temperature of the contact will not necessarily be the exact temperature reported by either of the sample or indenter thermocouples. To determine the true contact temperature, again, two methods exist. The first and simplest method is to place a thermocouple directly on the sample surface [34]. This is straightforward for relatively large samples. However, for smaller samples, a second method is required: to calibrate the thermal gradient between the indenter apex and the indenter thermocouple [33]. This allows the indenter temperature to be used as the reference temperature for the contact.

\subsection{Indenter Temperature Calibration}

Since the thermocouples for monitoring the indenter temperature cannot be located directly at the contact, a thermal gradient exists between the thermocouple and the tip of the indenter. This will be at a minimum if the thermocouple is directly clamped to the diamond (or other material) indenter, but some variation in manufacturing may still result in errors in indenter set temperature on the order of 5-40\% [9]. Measurement of this thermal gradient to calibrate

$$
p-7-
$$


the indenter temperature removes this uncertainty. There are several calibration methods available for this: indentation of thermocouples [9], Raman spectroscopy [9], and infrared thermometry.

Direct indentation of thermocouples at elevated temperature (Figure 4a) allows contact to be achieved at a known surface temperature. Matching the indenter temperature to this known surface temperature can be achieved by either thermal displacement drift measurements [7, 32] or direct temperature shift measurements [33] - Figure 3a. After performing this temperature matching procedure on a thermocouple at several different surface temperatures, the relationship between the known surface temperatures from the thermocouple and the temperatures at which the indenter apparently matches these temperatures can be ascertained. At high temperatures, the thermocouple material and indenter materials may react and damage the indenter, so care must be taken in selecting the thermocouple type to prevent this.

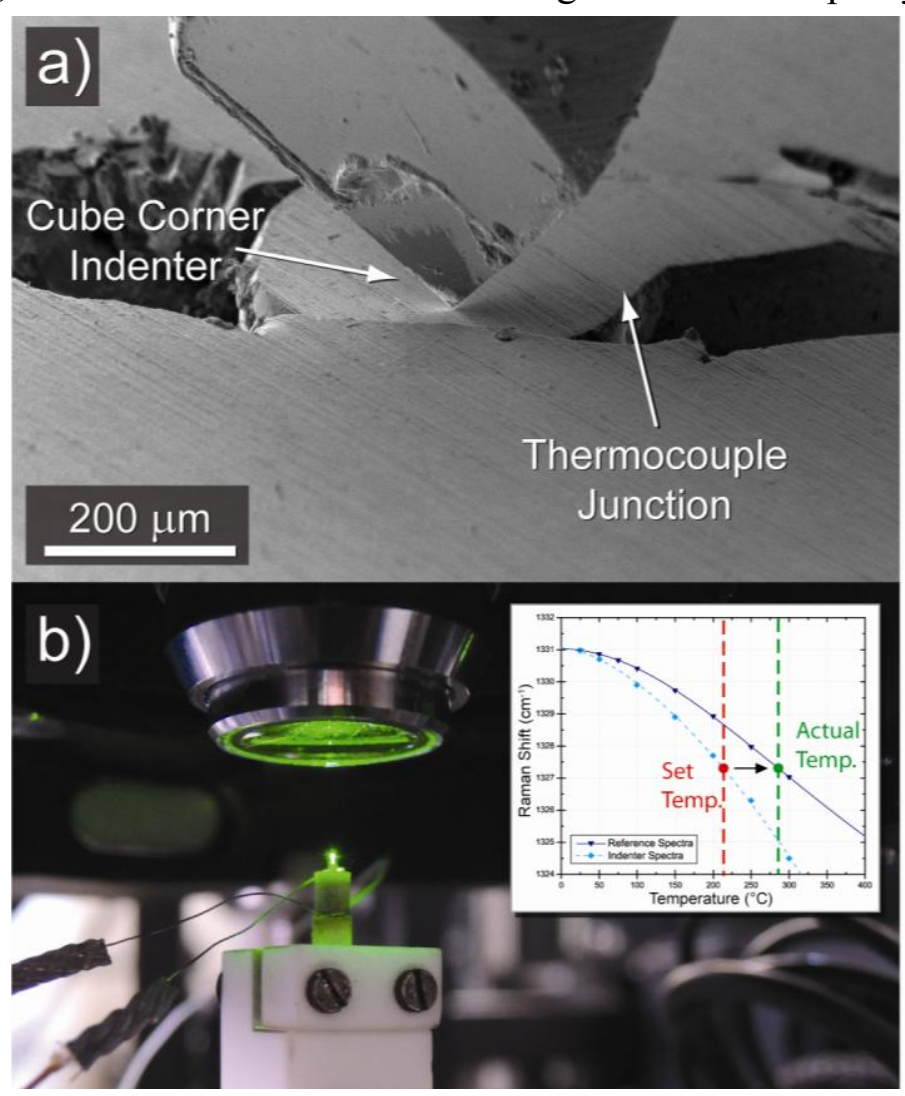

Figure 4: Techniques for characterizing and calibration of the true indenter tip temperature: a) indentation of a thermocouple and b) Raman spectroscopy.

Raman spectroscopy is a simple, non-contact method for measuring the indenter temperature. The relationships for Raman shift as a function of temperature are available in the literature for most indenter materials [10]. The slopes of these trends coupled with the precision of the shift measurements typically yield a temperature precision of $\sim 5^{\circ} \mathrm{C}$. If the laser spot can be focused directly onto the heated indenter, as shown in Figure $4 \mathrm{~b}$, the temperature of the indenter can be determined by comparison of the measured Raman peak shift to the literature values. The difference between the measured Raman values and the set indenter temperature will yield the indenter temperature calibration.

A third method for determining the indenter temperature is to use an infrared thermometer or camera. Infrared spot thermometers have a typical spot size of $\sim 0.5 \mathrm{~mm}^{2}$, but smaller spot sizes are achievable using high resolution infrared cameras. These sensors typically report an average temperature value over spot region with a precision of $\sim 2{ }^{\circ} \mathrm{C}$. However, the sensitivity of these measurements can be highly affected by the emissivity of the target material, which is a limitation in the case of a very low emissivity $(<3 \%)$ material such as

$$
p-8-
$$


diamond [35]. Extreme care must be taken to select only the signal from the diamond, so that it is not overwhelmed by the surrounding high emissivity $(\sim 90 \%)$ insulating cement.

\subsection{Thermal Drift Correction/Management}

Most modern nanoindentation systems implement a correction to their load-displacement data for ambient thermal drift due to temperature variations within the system frame. This is frequently implemented in a fashion similar to that shown in Figure 5. During unloading the load is held constant for a period of $\sim 60 \mathrm{~s}$ at $10 \%$ of the maximum applied load. The change in displacement as a function of time during this hold is measured, and then subtracted from the data.

This method is also valid for correcting small amounts of frame drift at elevated temperature if the indenter and sample temperatures are matched. If contact drift is occurring instead or in addition, then the drift may be non-linear and depend on the heat flow at the contact [9]. Hold periods prior to contact may also be used for measuring frame drift, but these will be insensitive to any possible contact drift. Another caveat is that this correction should only be used for indents made on a similar time scale to the drift hold period duration, since over longer time scales other variations may occur. If the disparity in temperature between the sample and the indenter is small and the system is stable (both types of drift are small), then the type of correction illustrated in Figure 5 can be performed with a minimum of error.

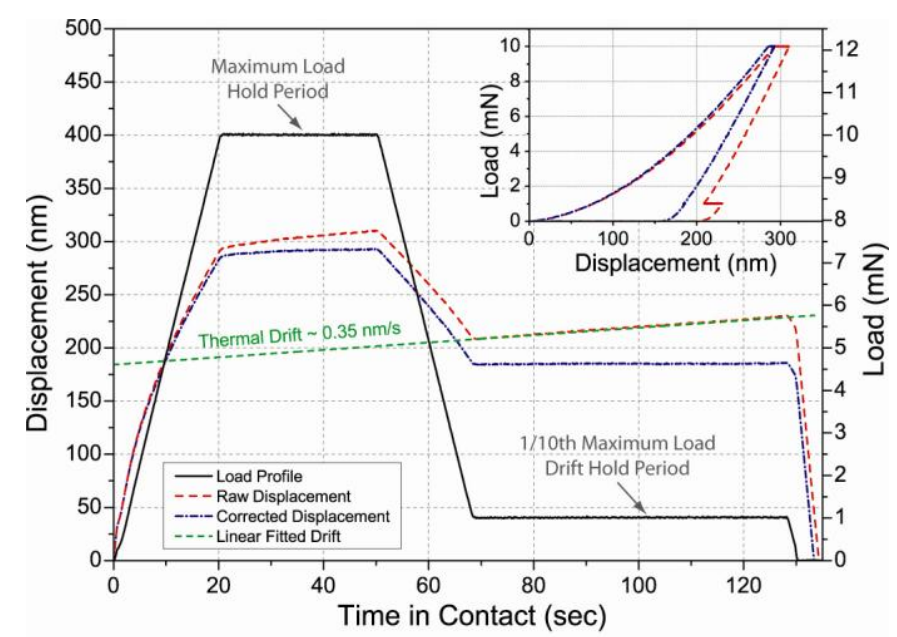

Figure 5: Standard method for correction of thermal drift.

Force modulation [36] can reduce the adverse effect of thermal drift, which is particularly critical for sub-micrometer indentations at elevated temperatures. Using force modulation, the stiffness of a contact can be determined during loading by dividing the applied force amplitude of a superimposed force oscillation by the amplitude of the resulting displacement, which is measured by a lock-in amplifier [22]. However, the force modulation technique needs to be used with care and with a thorough consideration of assumptions to be made. It was shown recently that there are quite a few sources for errors in particular for materials with large Modulus-to-Hardness ratios [37]. But this is a general problem of the method and not exclusive to high temperature indentation.

With respect to the technique's usefulness for high temperature indentation, three main use cases can be thought of: First, thermal drift is a critical issue for indentation creep experiments. Typically, the load is held at a constant value over extended periods of time while the tip displacement is monitored. Here, the creep rate can be determined directly from the stiffness measurements [36], the hardness, though, still depends on the contact area which is clearly affected by temperature drift. With the modulus of the material being known, the hardness of the material can be calculated. The approach as introduced by Weihs and Pethica [36], was applied by Syed Asif and Pethica [38] for extended hold times at elevated

$$
p-9-
$$


temperatures. Recently rediscovered by Maier et al. [39], the force modulation technique was applied to study the deformation behavior of nanocrystalline metals under constant load. While the assumption of the modulus being constant over time is very reasonable, the values of the elastic modulus for different temperatures might not be known.

The importance of low and constant drift rates has been pointed out above. If the drift rate is not constant during the experiment, the contact depth is prone to errors at small displacements because the drift correction is typically based on a hold segment at the end of unloading (see Figure 5). In this case, a constant modulus assumption can be used to determine the hardness at the different depths of the indent. This approach also minimizes the effects of temperature fluctuations during first contact between tip and sample. Here, the elastic modulus can be measured at large depths and then be used as an input parameter to evaluate the contact depth and thus hardness over the indentation depth. The application of the constant modulus assumption is illustrated in Figure 6. Here, the system temperatures were not sufficiently well stabilized and resulted in rather large changes in the displacement measurement. The stiffness, however, is not affected by the drift and can be used to determine the hardness (green curve in Figure 6a).
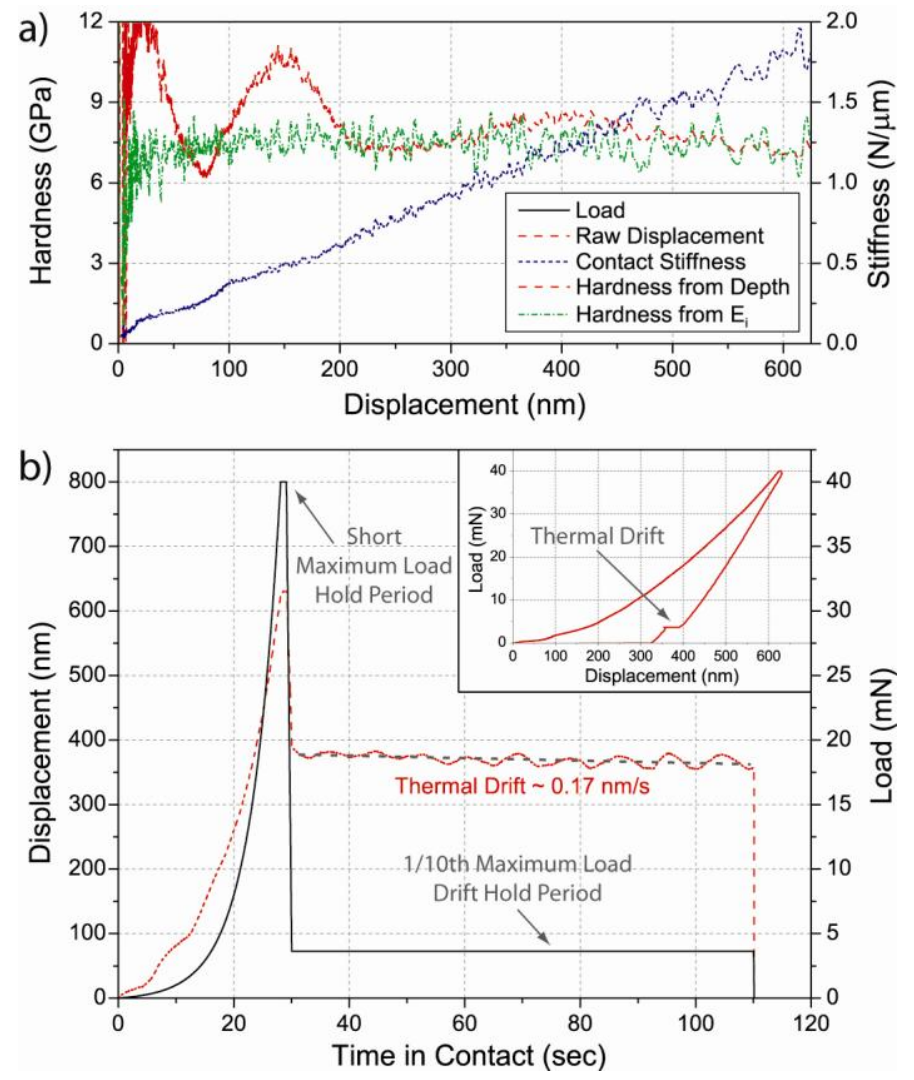

Figure 6: Dynamic force-modulated indentation into fused silica at nominal temperature of $300{ }^{\circ} \mathrm{C}$ without proper stabilization at the set temperatures showing a) dynamic indentation results as a function of displacement and b) the raw load and displacement as a function of time with the load-displacement curve inset. The dynamic method can be used to mitigate drift and temperature variation effects, which strongly influence the displacement measurement. Using the constant modulus assumption, the hardness of the material can still be determined.

The force modulation technique can also be used to determine the stiffness if the unloading part of the indentation curve cannot be analyzed, for example due to extensive creep resulting from an insufficient hold time before unloading. In this case the stiffness can be determined dynamically instead and used to evaluate the elastic modulus and hardness of the material.

Last, but not least, it can be helpful to consider the experimental time and length scales on which thermal drift may be affecting the results. The effects of drift can be minimized by either reducing the test time or by increasing the indentation size: a $0.1 \mathrm{~nm} / \mathrm{s}$ drift rate has a

$$
p-10-
$$


relatively small effect on a $100 \mathrm{~nm}$ indent performed in a $10 \mathrm{~s}$ duration or on a $3 \mu \mathrm{m}$ deep indent performed over 5 minutes. Depending on the user's measurement sensitivity requirements, this can be a useful consideration.

\section{High Temperature Testing in Vacuum}

\subsection{Overcoming Environmental Sample Surface Degradation}

A primary reason for pursuing high temperature nanoindentation is to allow the testing of engineering materials at operationally relevant conditions. While for many systems air is the operational environment, for others, such as tungsten for use in nuclear fusion reactors, the materials will operate at high temperatures in a vacuum vessel. For most applications in air, the behavior of the bulk material - away from the oxidized surface - is the parameter of interest, so a pristine surface is required to extract representative mechanical behavior of the bulk without the influence of an oxide. If sub-ambient tests are performed in air or inert atmospheres, water vapor can condense onto the sample surface to form a frost coating, causing similar issues to oxidation at higher temperatures.

Several mitigating solutions to atmospheric issues exist. An overpressure of shield gas composed of either high purity argon $[6,17]$ or argon with hydrogen can be used to surround the hot zone during testing. While inert atmospheres may be sufficient for mildly reactive materials, in many cases this is not sufficient. Dry nitrogen can be similarly used to prevent condensation at sub-ambient temperatures, but at the efficacy of this at very low temperatures is doubtful. For moderately elevated temperatures, a shielding liquid such as vacuum oil can be used in some systems to immerse the sample and prevent exposure to atmosphere [40]. However, the universal solution in all these cases is to remove the atmosphere completely and perform tests in high or ultra-high vacuum $[8,9]$.

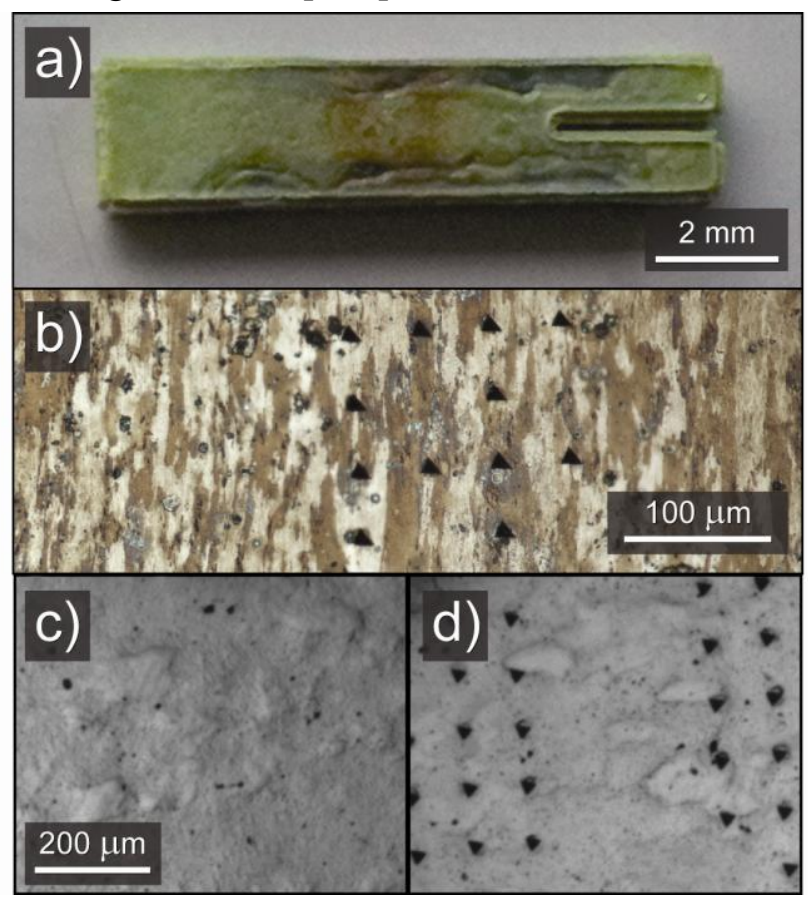

Figure 7: Optical micrographs of oxidation of tungsten samples in different environments: a) after heating at $750^{\circ} \mathrm{C}$ for 1 hour in argon atmosphere, b) after testing for 1 hour at $700^{\circ} \mathrm{C}$ in a reducing $\mathrm{He}-5 \% \mathrm{H}$ atmosphere, and a sample c) before and d) after testing at $750^{\circ} \mathrm{C}$ with no visible surface degradation.

The need for nanoindentation in high vacuum is well illustrated in Figure 7, which describes a series of experiments on tungsten. Tungsten is well known for having the highest melting point of any metal. However, less known is that tungsten is also extremely reactive with oxygen - reacting to form an oxide above $400{ }^{\circ} \mathrm{C}$ with that oxide subliming completely

$$
p-11-
$$


above $\sim 750{ }^{\circ} \mathrm{C}$. This makes it a good case to show the efficacy of different atmospheric measures to prevent sample surface degradation.

Figure 7a shows a tungsten sample after being tested in an argon atmosphere for $1 \mathrm{hr}$ at $700{ }^{\circ} \mathrm{C}$, the sample surface has significantly oxidized and no testing is possible. Figure $7 \mathrm{~b}$ shows a tungsten sample at $700{ }^{\circ} \mathrm{C}$ tested in a reducing atmosphere (Ar with $5 \% \mathrm{H}$ ). Although the oxidation rate was reduced significantly, oxidation of some grains persists and meaningful indentation is still not possible. In this case, the use of reducing atmospheres also raises questions of hydrogen embrittlement effects.

Another method for reducing the oxygen pressure within a chamber is to use heated pieces of a material with a high affinity for oxygen as a getter" to remove oxygen. Efforts to use a heated zirconium getters" inside a sealed chamber also proved insufficient to prevent oxidation of tungsten sample surfaces in commercial purity argon atmosphere.

The efficacy of high vacuum $\left(1 \times 10^{-6}\right.$ mbar $)$ for surface protection of tungsten at high temperatures is shown in Figure $7 \mathrm{c}$-e. Figure $7 \mathrm{c}$ shows an optical micrograph of a polycrystalline tungsten sample before testing, while Figure $7 \mathrm{c}$ and $7 \mathrm{~d}$ show the same sample after testing at $300{ }^{\circ} \mathrm{C}$ and $750{ }^{\circ} \mathrm{C}$ respectively for $\sim 100$ hours. Over a total experimental period of 500 hours ( 21 days) at elevated temperatures and under vacuum, no visible damage to the sample surface (as observed by the change in color due the formation of tungsten oxide in Figure $7 \mathrm{a}$ and $7 \mathrm{~b}$ ) was observed at any point during the experiments and surface hardness at room temperature was unchanged after the full cooling cycle. This demonstrates the necessity and effectiveness of high vacuum for surface protection at elevated temperatures to allow accurate nanoindentation of reactive metals.

\subsection{Oxidation/Wear of the Indenter}

Testing in vacuum not only protects samples but also overcomes issues associated with damage to indenter; due to oxidization of the diamond, nitride or carbide material used for the tip. Oxidation damage to diamond indenters at $>400{ }^{\circ} \mathrm{C}$ [17] is a primary limiting factor in maximum temperature for most non-vacuum nanoindentation systems. Most other non-oxide indenter materials are also susceptible to oxidation damage at similar or slightly higher temperatures than diamond [10]. The secondary limiting factor is diamond's tendency to react with ferrous or carbide-forming early transition metals [10].

Figure 8 illustrates the relative levels of damage caused by indentation in different high temperature conditions. At lower temperatures, $\leq 400{ }^{\circ} \mathrm{C}$, diamond indenters can be nominally stable for years of operation and experience little damage, as shown in Figure 8a. However, at higher temperatures most indenter materials are susceptible to oxidative damage. Figure $8 \mathrm{~b}$ shows an AFM image of a diamond indenter heated for $90 \mathrm{~min}$ at $900{ }^{\circ} \mathrm{C}$ in commercial purity argon. This demonstrates the importance of vacuum systems for indentation testing at the highest temperatures.

Use of indenter materials such as cubic boron nitride or tungsten carbide can be a useful alternative in the cases where diamond is likely to unfavorably react with the sample material at high temperatures. However, invariably these materials are not as hard or durable as diamond indenters [10]. Figure $8 \mathrm{c}$ shows a secondary electron (SE) micrograph depicting a worn cubic boron nitride (cBN) tip after performing $\sim 1000$ indentations of $2 \mu \mathrm{m}$ depth on a tungsten sample in vacuum from 21 to $750{ }^{\circ} \mathrm{C}$. The indenter tip is severely blunted by this loading cycle and pitting type damage (similar to that observed by Wheeler et al. [17] on diamond) is seen on the indenter faces. It is clear that care must be taken in selecting the correct tip for specific experiments at high temperatures and that careful monitoring of tip wear during high temperature indentation experiments - even in vacuum - is important. The worst case scenario is illustrated in Figure 8d, where a diamond Vickers indenter is consumed as a result of high vacuum indentation of steel at elevated temperatures.

$$
p-12-
$$




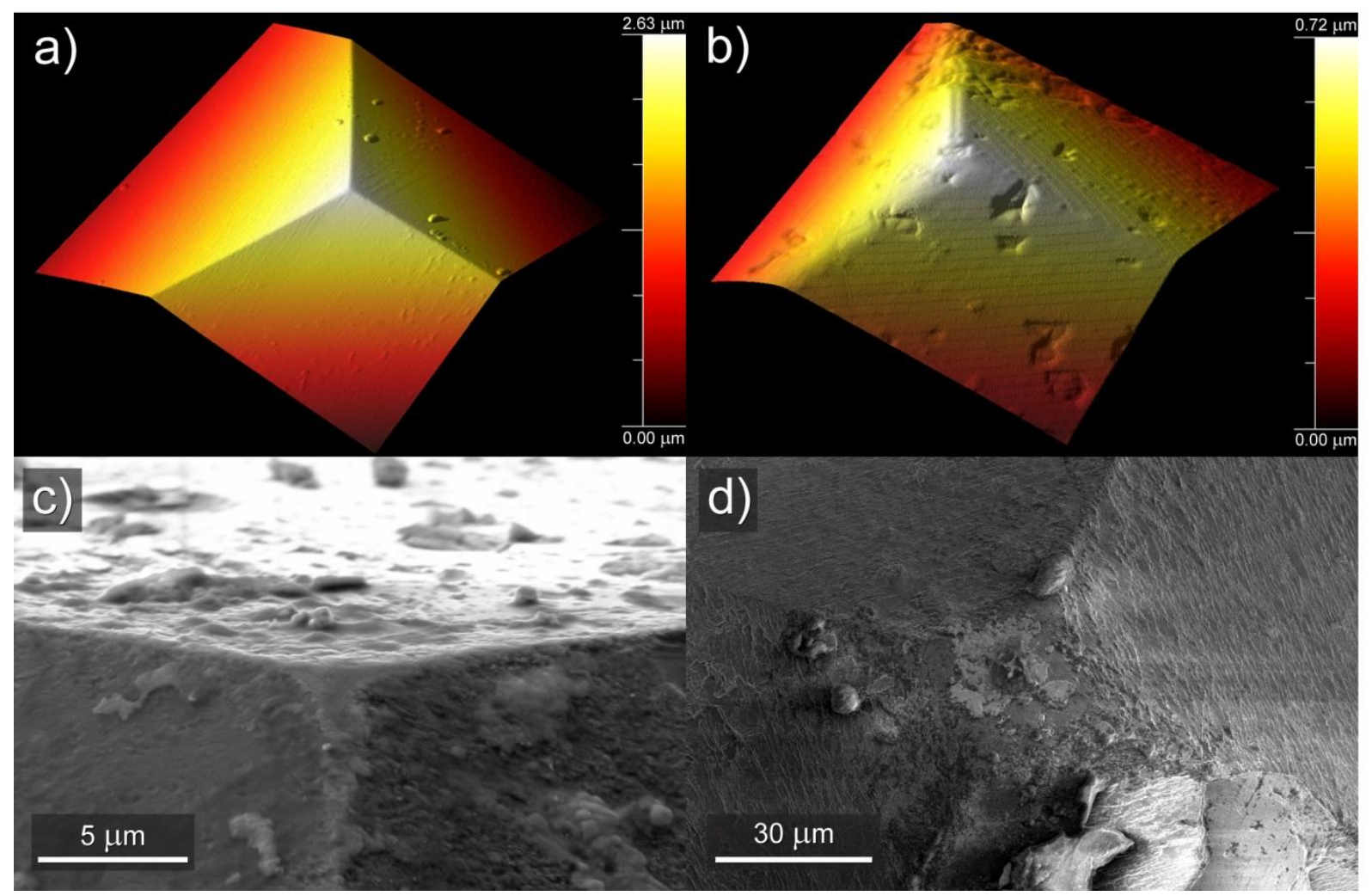

Figure 8: Indenter tips after usage in high temperature conditions: a) AFM scan of a diamond Berkovich undamaged after long term usage at temperatures $<400{ }^{\circ} \mathrm{C}$ [17], b) AFM scan of a diamond Berkovich after 90 min at $900^{\circ} \mathrm{C}$ in commercial purity argon [17], c) SE micrograph of a cBN Berkovich after 1000 indentations into tungsten between 20 and $700^{\circ} \mathrm{C}$, and d) SE micrograph of a diamond Vickers after $\sim 100$ indentations into steel between 100 and $600{ }^{\circ} \mathrm{C}$.

The severity of the indenter wear shown in Figure 8 illustrates one of the key remaining problems for high temperature nanoindentation: is there any material which can survive the high stresses and temperatures of experienced by a nanoindenter in these conditions? So far, the answer is no. Cubic boron nitride is the second hardest material after diamond, and its blunting at these temperatures makes $\mathrm{cBN}$ indenters a rapid consumable. Nanoindentation testing requires an extremely sharp tip radius for accurate testing at low depths, so only three strategies remain for testing at the highest temperatures: micro-indentation to depths where the blunting is negligible, microcompression using a flat punch, and mutual indentation using crossed wedges.

\subsection{Technical Issues of Vacuum Nanoindentation}

Nanoindentation testing in vacuum has a number of unique technical issues which need to be considered during their design and operation. In situ SEM nanoindentation systems have the advantages that the vacuum pumps are already mechanically isolated from the chamber to prevent vibration and the coarse positioning stages and observational capabilities are provided by the microscope manufacturers. In other systems, the isolation of noise from the vacuum pumps can be a key issue. Mechanical noise on vacuum nanoindentation systems can come from two main sources: water-cooling and vacuum pumps. Water-cooling noise arises from turbulence in the flow of the coolant. This can be reduced by using smooth walled pipes (rather than accordion/bellowed pipes) and laminar flow stabilizer reservoirs. Other solutions can include a gravity fed cooling system where no active water pumping on the indenter is required. Mechanical vibration from the vacuum pumps can typically be overcome by using passive damping of the pumps and by situating them away from the instruments. 
The MML NanoTest Xtreme is a good example of a nanoindentation system modified for testing in high vacuum $\left(1 \times 10^{-6} \mathrm{mBar}\right)$. It consists of a standard MML NanoTest system (Figure $2 \mathrm{~b}$ ) mounted inside a vacuum chamber. Positioning stages and motors were replaced with vacuum-compatible versions using non-volatile lubricants. In the case of the MML system, the pendulum requires damping to reduce its susceptibility to mechanical vibration. In air, this is provided by two glass plates, but in vacuum this had to be replaced by a magnet and copper block to allow for eddy current damping.

The thermal management of nanoindentation systems in vacuum is also inherently more difficult than in either air or inert atmospheres as convection as a means of equilibrating temperatures is removed. Thus, bringing the key parts of the system (typically sample and indenter) to thermal equilibrium is more difficult. Thermal variations introduced are due mainly to either the change in pressure during pumping to vacuum, which results in cooling of small thermal mass components due to the ideal gas law, or to imposed changes to the sample and/or indenter heaters, i.e. stabilization at elevated temperatures. In this case, it is preferred that large frame components are water-cooled and have good thermal conductivity and that only the regions nearest the hot zone are insulating. This allows the thermal gradients in the frame to stabilize quickly, while the gradients near the hot zone are contained and independently controlled. At higher temperatures $\left(>500^{\circ} \mathrm{C}\right)$ radiative heat transfer between the sample, indenter, and other components can make accurate control of the temperature more difficult. In this case, special care must be taken to ensure full equilibrium is reached before testing commences.

\section{In-Situ High Temperature Testing}

\section{$5.1 \quad$ Technical Issues}

Testing in situ in the electron microscope shares many of the technical challenges of vacuum nanoindentation. The scanning electron beam, electron detectors, and line-of-sight needed for observation introduce several new issues. First, the electron beam is deflected by any electromagnetic fields, so an alternating current supplied to a resistance heater inside the SEM will produce an oscillating deflection of the electron beam and produce a wobbly" image. Extensive shielding or image processing to synchronize the electron beam scan acquisition to the alternating current frequency may mitigate this. However, direct current is preferred instead, so the deflection of the beam is constant and produces a correctable beam shift. Similar, though weaker, noise will be observed if the electrical components within the system are not thoroughly grounded. Otherwise, the exterior wires will transmit outside electronic noise into the microscope. Furthermore, mechanical vibrations may also be transferred into the chamber by cables, which seems simplistic but can nevertheless be difficult to handle.

Another source of imaging noise during high temperature nanoindentation in situ is radiation. At temperatures $>525{ }^{\circ} \mathrm{C}$, many materials begin radiating infrared light and thermionic electrons [41]. This can greatly reduce imaging contrast at elevated temperatures, since the signal from the thermally emitted electrons will overwhelm the secondary electrons from a small, low beam current spot. Use of high accelerating voltages and large spot sizes or use of a special electron detector with energy filtering is required for imaging at these temperatures.

Finally, the electron beam requires line-of-sight between to the region of interest. This requires serious consideration on the design of experiments, as well as the system design. For indentation experiments, where the surface deformation is the feature of interest, an indenter with a higher aspect ratio, such as the Cube Corner geometry, will provide a wider open angle with superior viewing quality compared to a low aspect ratio indenter like a Berkovich or Vickers geometry [9]. In both of these cases, an inclined observational angle like that shown in Figure $4 \mathrm{a}$ is desirable, since it facilitates observation of positioning in both $\mathrm{X}$ and $\mathrm{Y}$

$$
p-14-
$$


directions relative to the sample surface. However, there are some test geometries, e.g. microcompression or bending on the sample edge, where direct normal observation might be preferred. In this case, an ideal system would be one which can be tilted for oblique observation during positioning and then tilted back for normal observation for testing.

\subsection{Observational Capabilities}

In many cases, ex situ, post mortem observation of a sample will suffice. If the positioning and error-checking benefits can be ignored, then in situ testing simply makes imaging more convenient. However, Figure 9 illustrates a situation where in situ observation is critical: monitoring crack growth for fracture toughness measurements. In this case, the fracture toughness of metal-ceramic multilayers at elevated temperature was investigated to determine if the previously observed extrusion behavior of the metal layers would toughen the material at elevated temperatures. Ex situ observation is not feasible for these tests, as the cracks will close upon unloading.

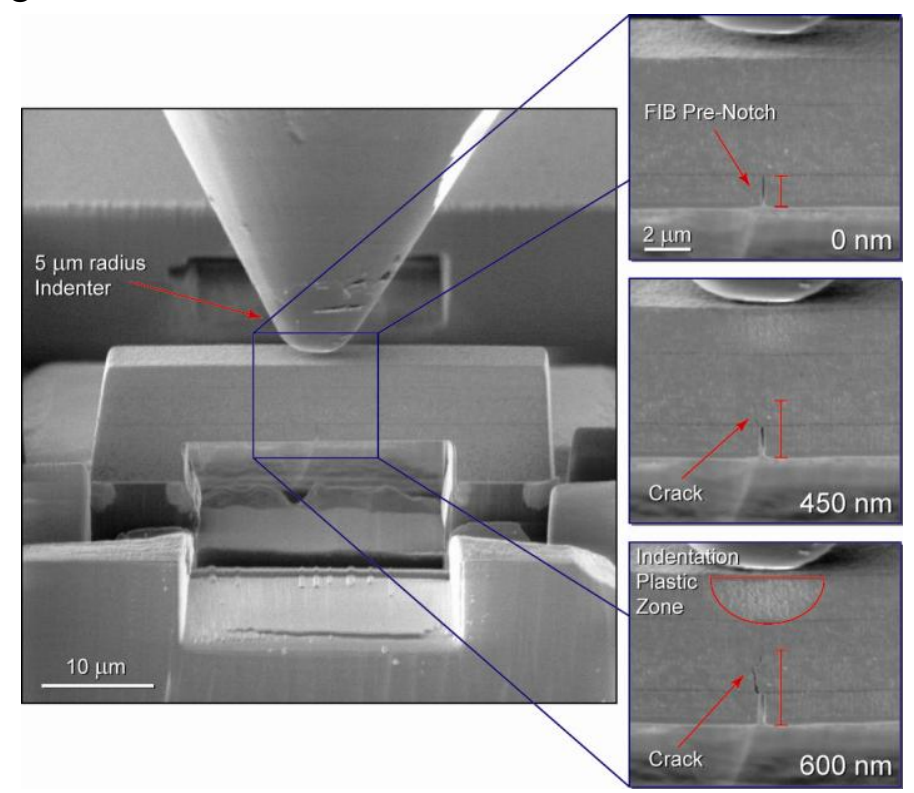

Figure 9: In situ observation of crack propagation in a 50/50nm Cu-TiN multilayer during bending of bridge at $200{ }^{\circ} \mathrm{C}$ in the SEM with crack extension shown in insets at several bending displacements.

Furthermore, by combining in situ testing in the SEM with elevated temperature techniques [29], a unique and powerful capability for observing and measuring thermally activated deformation mechanisms can be achieved. For example, slip systems for plastic deformation can be directly observed [30] without secondary imaging. Various transitions such as phase transformations [42] and glass transitions [43] or other chemical reactions can all be directly recorded on video, not to mention deformation twinning, fracture behavior, crack lengths and ductile-brittle transformations.

Direct observation of an experiment in the SEM in combination with digital image correlation (DIC) offers the additional advantage of determining the deformation directly on the sample being tested. For example, during microcompression testing the instantaneous pillar shape together with the load applied by the indenter gives much better access to the local and instantaneous applied stress $[44,45]$ than the usually determined simple engineering stress, which assumes that the pillar deforms symmetrically. Furthermore, with a view to temperature instabilities and drift or frame compliance it may be advantageous to determine the deformation or tip displacement directly from video frames. Recently, DIC has been implemented as the displacement measurement system in a high vacuum HT microindenter, which has been designed to be operated remotely in a hot cell [46]. Uncertainties in sample 
mounting and compliance can be reduced by measuring the relative displacement between the tip and the sample.

\section{Emerging High Temperature Techniques}

\subsection{Rapid Thermo-Mechanical Cycling}

The small sample volumes used in nanoindentation testing have a small thermal mass, making them ideal for rapid thermal cycling. Investigations on thermo-mechanical fatigue of thin films are a very useful tool for the electronics industry in order to determine the lifetime of metallizations within semiconductor packaging. Laser-heated systems such as that shown in Figure $2 \mathrm{~d}$ are ideal for this due to the high heating rates achievable $\left(2400^{\circ} \mathrm{C} / \mathrm{min}\right)$. Figure 10 shows a thermal cycling experiment performed between 100 and $450{ }^{\circ} \mathrm{C}$ with a heating rate of $400^{\circ} \mathrm{C} / \mathrm{min}$ and a cooling rate of about $275^{\circ} \mathrm{C} / \mathrm{min}$ and a dwell time of $30 \mathrm{~s}$ at maximum temperature. These values were chosen to allow comparison to previous work in a tube furnace [47, 48]. Higher cooling rates were not achievable with the current water and aircooling in the system. This yielded an experiment time of $\sim 23$ days for 10,000 cycles.
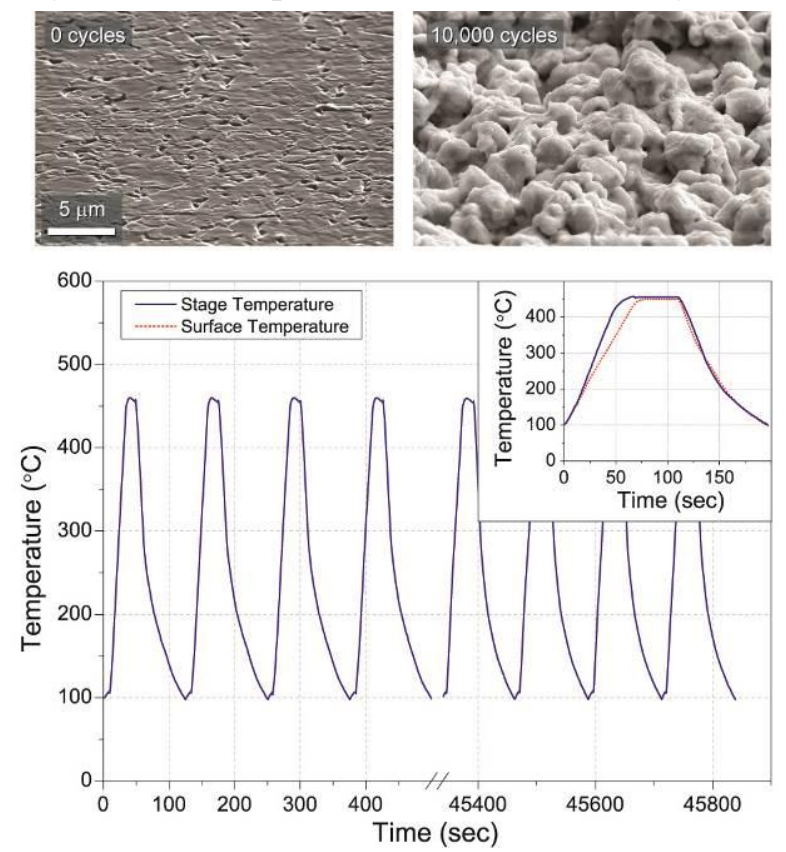

Figure 10: Stability of the thermal cycling over $>300$ thermal cycles with the surface temperature vs. stage controller temperature inset and with secondary electron micrographs before and after cycling shown above.

To calibrate the surface temperature of the sample during thermal cycling, a second thermocouple was connected to the surface of a silicon test sample (Figure 10 - inset). This allowed tuning of the PID controller to optimize the cycling parameters to prevent overshoot. A reducing gas atmosphere was used to prevent oxidation of the samples at elevated temperatures.

The goal of this system is to investigate the mechanical properties of $\mathrm{Cu}$ and $\mathrm{Al}$ thin films deposited on Si substrates after thermal cycling. However, thermal cycling induced significant roughening of the sample surfaces (Figure 10), so investigations were limited to microstructural evaluation with SEM and EBSD after thermal cycling [49]. This showed significant grain rotation takes place, which would lead to mechanical property variation due to the change in texture. Further experiments are planned on this sample with a polishing step to decrease the roughness of the cycled samples for measuring mechanical properties. 


\subsection{Determination of Interfacial Thermal Resistance}

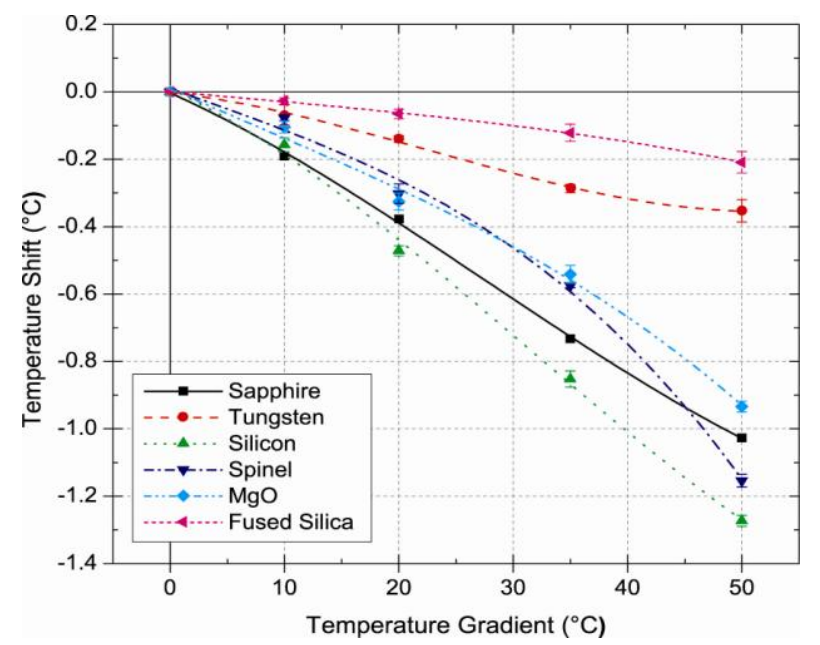

Figure 11: Temperature shifts of a flat punch diamond indenter as a function of temperature gradient for a $63 \mathrm{\mu m}^{2}$ contact at a pressure of $50 \mathrm{MPa}$ on several different materials.

A chief limitation to high temperature nanoindentation testing is error due to contact thermal drift due to heat transfer between indenter and sample. In order to examine the relationship between the heat flow and materials properties, the heat loss from a heated diamond indenter to several sample materials at ambient temperature has been measured by careful thermometry under highly controlled conditions: constant cross sectional area, constant contact pressure, extremely low roughness, single crystalline or amorphous samples, and high vacuum. The maximum temperature shift during a flat punch indentation of the same loading profile on several different samples with the indenter at different temperatures under constant heating power is shown in Figure 11.

\begin{tabular}{lccccc}
\hline \hline \multicolumn{1}{c}{ Material } & $\begin{array}{c}\text { Density } \\
\left(\mathrm{g} / \mathrm{cm}^{3}\right)\end{array}$ & $\begin{array}{c}\text { Specific Heat } \\
\left(\mathrm{J} \cdot \mathrm{g}^{-1} \cdot{ }^{\circ} \mathrm{K}^{-1}\right)\end{array}$ & $\begin{array}{c}\text { Thermal } \\
\text { Conductivity } \\
\left(\mathrm{W} \cdot \mathrm{m}^{-1} \cdot{ }^{\circ} \mathrm{K}^{-1}\right)\end{array}$ & $\begin{array}{c}\text { Thermal } \\
\text { Diffusivity } \\
\left(\mathrm{mm}^{2} \cdot \mathrm{s}^{-1}\right)\end{array}$ & $\Delta T / T$ \\
\hline Diamond, type IIa & 3.51 & 0.52 & 2000 & -- & -- \\
Fused Silica, $\mathrm{SiO} \mathrm{O}_{2}$ & 2.20 & 0.70 & 1.38 & 0.89 & 0.004 \\
Magnesia [001], $\mathrm{MgO}$ & 3.58 & 1.03 & 60.00 & 16.27 & 0.020 \\
Sapphire [0001], $\mathrm{Al}_{2} \mathrm{O}_{3}$ & 4.02 & 0.75 & 42.00 & 13.93 & 0.021 \\
Silicon [001] & 2.33 & 0.70 & 130.00 & 79.38 & 0.017 \\
Spinel [001], $\mathrm{MgAl}_{2} \mathrm{O}_{4}$ & 3.58 & 1.08 & 24.00 & 6.23 & 0.025 \\
Tungsten [001] & 2.20 & 0.70 & 1.38 & 0.89 & 0.007 \\
\hline \hline
\end{tabular}

Table 1: Summary of room temperature thermomechanical properties of materials [50-58].

If the slope of the temperature shift vs. temperature gradient $(\Delta T / T)$ is assumed to be linear for each material, a comparison between the magnitude of the heat flow and the different thermal properties of the materials can be made (Table 1). Thus, it is observed that the magnitude of the heat flow is not a direct function of either the thermal conductivity, specific heat, or thermal diffusivity of the sample material. Instead, it apparently depends on the interfacial thermal resistance between the indenter and sample materials or the degree to which the thermal transport mechanisms of the diamond and the sample match. The values of $\Delta T / T$ are only qualitative at this point, due to the complicated geometry of the heated indenter with several different materials and interfaces between the thermocouple and the contact. A more simplified geometry to extract quantitative heat flow values is planned for further work exploring this relationship. 


\section{3}

\section{Transient Plasticity Measurements: Strain Rate Jumps, Creep, and Stress Relaxation}
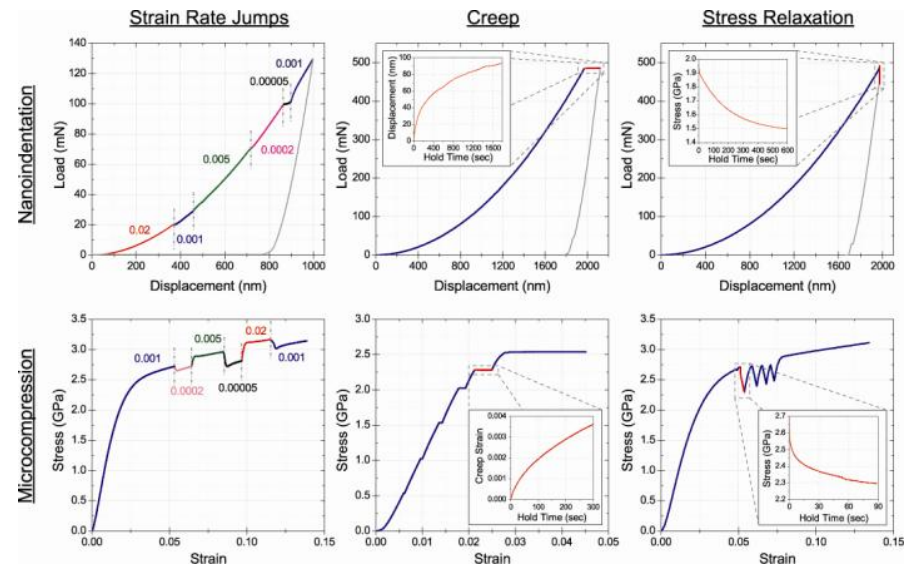

Figure 12: Exemplar transient plasticity tests on nanocrystalline Nickel at ambient temperature.

Measurement of transient plasticity behavior is the primary mechanical method for determining deformation mechanisms [59]. These tests consist of varying strain rate, temperature, or stress in a variety of different ways to determine plasticity parameters. There are three main conventional, macro-scale varieties of these tests: strain rate jumps, creep, and stress relaxation. Variable temperature nanomechanical testing now enables the extension of these techniques to small length scales as well. Strain rate jump testing has already been successfully demonstrated at elevated temperatures in both nanoindentation [60] and microcompression geometries [61].

The successful development of creep testing at small scales has been more elusive. The difference between the complicated stress state of indentation creep and the simple case of bulk uniaxial creep is makes the comparison between these two measurements unlikely to agree. This was observed several decades previously for the case of hot hardness testing [62], where residual indentation size was measured as a function of time rather than indenter penetration depth. In this case, it was noted that pyramidal, conical and spherical indenters all fail to yield accurate creep data due to the expanding plastic zone under the indenter constantly interrogating new material, such that primary creep behavior dominates. Recent studies using finite element analysis have noted the same problems [63]. Impression creep using flat punch indenters and pure uniaxial loading geometries such as micropillars shows more promise [64, 65], but these techniques have not yet been systematically established in relation to the existing bulk literature yet.

An alternative to creep testing is stress relaxation testing, where the strain is kept constant and stress allowed to relax, rather than the strain developing under a constant stress. For indentation testing, this may allow a more constant volume to be interrogated rather than an expanding cavity. Both creep testing and stress relaxation testing require a highly stable system, so both a thermally stable system and dynamic drift correction methods may be required for longer term measurements. Development of these techniques, which are exemplified for the case of nanocrystalline $\mathrm{Ni}$ in Figure 12, is an active area of research. In the nanoindentation geometry, the experiments all are based on the force modulation technique (see section 3.4). While for the strain rate jump tests, the contact stiffness is used in conjunction with the displacement measurement to determine the hardness, the indentation creep experiment assumes the elastic modulus is known and circumvents the displacement measurement. The stress relaxation test is probably the most challenging one as it uses the dynamic contact stiffness itself to maintain a constant contact depth and measures the reduction of the load. The equivalent pillar experiments are more straightforward yielding stress and strain values right away.

$$
p-18-
$$




\section{Summary and Future Challenges}

Nanoindentation testing at elevated and increasingly higher temperatures is feasible due to several advances in thermal management techniques. Chief among these is the independent heating of the indenter and sample to allow testing without heat transfer and the resulting contact thermal drift during measurement. Stabilization of the system frame using insulating components, heat sinks, low coefficient of thermal expansion materials and water-cooling removes the other main contribution to thermal drift during measurements. For measurements in vacuum and in situ, similar requirements are necessary, but water-cooling of components and careful isolation of electrical signals are more significant, respectively, for these techniques.

To achieve accurate nanoindentation measurements at higher temperatures $\left(>750{ }^{\circ} \mathrm{C}\right)$, several challenges still remain. First, and simplest, the heating elements and power supplies need to be improved to allow these temperatures to be achieved with low enough noise that fluctuations do not influence measurements, and the complementary water-cooling technologies to contain these temperatures without introducing further noise must also be developed. The most outstanding challenge for high temperature indentation, however, is identifying or developing an indenter material which can withstand these temperatures without rapidly blunting after only a few tests. Currently, diamond and boron carbide are the materials of choice due to their excellent retained hardness at high temperatures [10]. Both of these materials will likely require high to ultra-high vacuum to prevent oxidation at these temperatures. At the highest temperatures $\left(>1200^{\circ} \mathrm{C}\right)$, it is unlikely that any indenter material will survive without blunting, therefore either the mutual indentation technique [66, 67] where crossed cylinders or wedges are pressed together to produce an indentation, microindentation to depths where the indenter is still effectively sharp, or the microcompression technique, where a flat punch compresses a small pillar of material, may be required.

In addition to high temperatures, indentation testing at sub-ambient temperatures is also expected to grow in popularity. Similar thermal management and temperature matching techniques are required for this technique as for elevated temperature. Difficulties with condensation and frost formation on the sample and indenter initially limited this technique, but recent availability of controlled atmosphere [68] and vacuum techniques [69-71] have surpassed this difficulty and allowed testing at near liquid nitrogen temperatures.

Lastly, the final achievement in development of high temperature nanoindentation will be the reliable automation of all variable temperature testing. This will require the full calibration of temperature gradients within the components of each system, automatic temperature matching of sample and indenter, calibrated stabilization times, and use of established drift correction methods to reduce the impact of any minor residual drift due to thermal calibration errors. This is all currently achievable with the techniques described in this work, and several commercial systems have implemented some of the recommended techniques in an automated fashion. This has streamlined testing significantly, but a highly skilled user is still currently required to supervise or perform the variable temperature testing. By implementing the remaining techniques, it is believed that the widespread popularity of conventional nanoindentation testing will extend to variable temperature techniques in a similar fashion that the availability of automated testing and analysis facilitated nanoindentation's initial rise to its current levels. This will facilitate a wide variety of applications as well as combinations with complementary characterization techniques to investigate the materials' behavior. 


\section{Acknowledgements}

JMW would like to thank Dr. J-M. Breguet and Dr. R. Rabe of Alemnis and Mr. D. Frey \& Mr. G. Buerki of EMPA for technical assistance with the In Situ Indenter and S. Hostettler of Synton-MDP AG, Nidau, Switzerland for help with the joint development of the heated indenter tips used in this work. Figure $3 b$ is reprinted with permission from Review of Scientific Instruments, 84 (4), 045103. Copyright 2013, AIP Publishing LLC. Figure 4a is reprinted with permission from Philosophical Magazine 92 (25-27), 3128-3141. Copyright 2012, Taylor and Francis LLC. Figure $8 \mathrm{a}$ and $8 \mathrm{~b}$ are reprinted from Diamond and Related Materials, 19 (11), 1348-1353, Copyright 2010, with permission from Elsevier.

JMW would like to acknowledge the on-going collaboration with Dr. S. Pathak of Los Alamos National Laboratory which produced Figure 9. This work was performed, in part, at the Center for Integrated Nanotechnologies, an Office of Science User Facility operated for the U.S. Department of Energy (DOE) Office of Science. Los Alamos National Laboratory, an affirmative action equal opportunity employer, is operated by Los Alamos National Security, LLC, for the National Nuclear Security Administration of the U.S. Department of Energy under contract DE-AC52-06NA25396. Furthermore JMW would like to acknowledge the contribution of Dr. G. Mohanty of EMPA to Figure 11.

DEJA acknowledges the support of the Royal Academy of Engineering through a Research Fellowship and EPSRC grant EP/H018921/1. DEJA would like to thank Professor S.G. Roberts, Dr. T.B. Britton and Mr. J. Gibson whom he has collaborated with on high temperature indentation, and Mr. A. Harris, MicroMaterials UK, for technical support.

RS would like to acknowledge the financial support through the European m-era.net project FASS (DFG grant No SCHW 855/5-1). Furthermore, RS would like to thank Dr. Jonas Groten for technical assistance with the HT setup. 


\section{Figure Captions}

Figure 1: Maximum published indentation temperatures for various system configurations and publications per year in recent years [18].

Figure 2: Schematics of the different heating arrangements commercially available from a) Alemnis AG, b) MicroMaterials Ltd., c) Nanomechanics Inc., d) and SURFACE GmbH laser heating for a Keysight system.

Figure 3: Indenter-sample temperature matching procedures using a) thermal displacement drift and b) indenter temperature shift magnitudes to determine the isothermal contact temperature.

Figure 4: Techniques for characterizing and calibration of the true indenter tip temperature: a) indentation of a thermocouple and b) Raman spectroscopy.

Figure 5: Standard method for correction of thermal drift.

Figure 6: Dynamic force-modulated indentation into fused silica at nominal temperature of $300{ }^{\circ} \mathrm{C}$ without proper stabilization at the set temperatures showing a) dynamic indentation results as a function of displacement and $b$ ) the raw load and displacement as a function of time with the load-displacement curve inset. The dynamic method can be used to mitigate drift and temperature variation effects, which strongly influence the displacement measurement. Using the constant modulus assumption, the hardness of the material can still be determined.

Figure 7: Optical micrographs of oxidation of tungsten samples in different environments: a) after heating at $750{ }^{\circ} \mathrm{C}$ for 1 hour in argon atmosphere, b) after testing for 1 hour at $700{ }^{\circ} \mathrm{C}$ in a reducing $\mathrm{He}-5 \% \mathrm{H}$ atmosphere, and a sample c) before and d) after testing at $750{ }^{\circ} \mathrm{C}$ with no visible surface degradation.

Figure 8: Indenter tips after usage in high temperature conditions: a) AFM scan of a diamond Berkovich undamaged after long term usage at temperatures $<400{ }^{\circ} \mathrm{C}$ [17], b) AFM scan of a diamond Berkovich after $90 \mathrm{~min}$ at $900{ }^{\circ} \mathrm{C}$ in commercial purity argon [17], c) SE micrograph of a cBN Berkovich after $\sim 1000$ indentations into tungsten between 20 and 700 ${ }^{\circ} \mathrm{C}$, and d) SE micrograph of a diamond Vickers after $\sim 100$ indentations into steel between 100 and $600{ }^{\circ} \mathrm{C}$.

Figure 9: In situ observation of crack propagation in a 50/50nm Cu-TiN multilayer during bending of bridge at $200{ }^{\circ} \mathrm{C}$ in the SEM with crack extension shown in insets at several bending displacements.

Figure 10: Stability of the thermal cycling over $>300$ thermal cycles with the surface temperature vs. stage controller temperature inset and with secondary electron micrographs before and after cycling shown above.

Figure 11: Temperature shifts of a flat punch diamond indenter as a function of temperature gradient for a $63 \mu \mathrm{m}^{2}$ contact at a pressure of $50 \mathrm{MPa}$ on several different materials.

Figure 12: Exemplar transient plasticity tests on nanocrystalline Nickel at ambient temperature. 


\section{References}

[1] McElhaney KW, Vlassak JJ, Nix WD. Determination of indenter tip geometry and indentation contact area for depth-sensing indentation experiments. Journal of Materials Research. 1998;13:1300-6.

[2] Oliver WC, Pharr GM. An Improved Technique for Determining Hardness and ElasticModulus Using Load and Displacement Sensing Indentation Experiments. Journal of Materials Research. 1992;7:1564-83.

[3] Beake BD, Smith JF. High-temperature nanoindentation testing of fused silica and other materials. Philosophical Magazine A. 2002;82:2179-86.

[4] Schuh CA, Packard CE, Lund AC. Nanoindentation and contact-mode imaging at high temperatures. Journal of Materials Research. 2006;21:725-36.

[5] Duan Z, Hodge A. High-temperature nanoindentation: New developments and ongoing challenges. JOM Journal of the Minerals, Metals and Materials Society. 2009;61:32-6.

[6] Trenkle JC, Packard CE, Schuh CA. Hot nanoindentation in inert environments. Review of Scientific Instruments. 2010;81:073901.

[7] Everitt NM, Davies MI, Smith JF. High temperature nanoindentation - the importance of isothermal contact. Philos Mag. 2011;91:1221-44.

[8] Korte S, Stearn RJ, Wheeler JM, Clegg WJ. High temperature microcompression and nanoindentation in vacuum. Journal of Materials Research. 2011;27:167-76.

[9] Wheeler JM, Michler J. Elevated temperature, nano-mechanical testing in situ in the scanning electron microscope. Review of Scientific Instruments. 2013;84:045103.

[10] Wheeler JM, Michler J. Invited Article: Indenter materials for high temperature nanoindentation. Review of Scientific Instruments. 2013;84:101301.

[11] Beake BD, Fox-Rabinovich GS. Progress in high temperature nanomechanical testing of coatings for optimising their performance in high speed machining. Surface and Coatings Technology. 2014.

[12] Bahr DF, Wilson DE, Crowson DA. Energy considerations regarding yield points during indentation. Journal of Materials Research. 1999;14:2269-75.

[13] Poisl WH, Oliver WC, Fabes BD. Journal of Materials Research. 1995;10:2024-32.

[14] Lucas BN, Oliver WC. Time Dependent Indentation Testing At Non-Ambient Temperatures Utilizing the High Temperature Mechanical Properties Microprobe. MRS Online Proceedings Library. 1994;356:null-null.

[15] Syed Asif SA, Pethica JB. Nano-Scale Indentation Creep Testing at Non-Ambient Temperature. The Journal of Adhesion. 1998;67:153-65.

[16] Smith JF, Zheng S. High temperature nanoscale mechanical property measurements. Surface Engineering. 2000;16:143-6.

[17] Wheeler JM, Oliver RA, Clyne TW. AFM observation of diamond indenters after oxidation at elevated temperatures. Diam Relat Mater. 2010;19:1348-53.

[18] SciVerse ${ }^{\circledR}$ Scopus ${ }^{\circledR}$. Elsevier B.V.; 2014.

[19] Binnig G, Quate CF, Gerber C. Atomic force microscope. Physical review letters. 1986;56:930.

[20] Euler R, Memmert U, Hartmann U. Fiber interferometer-based variable temperature scanning force microscope. Review of Scientific Instruments. 1997;68:1776-8.

[21] Prilliman SG, Kavanagh AM, Scher EC, Robertson ST, Hwang KS, Colvin VL. An insitu hot stage for temperature-dependent tapping-mode ${ }^{\mathrm{TM}}$ atomic force microscopy. Review of Scientific Instruments. 1998;69:3245-50.

$$
p-22-
$$


[22] DiBattista M, Patel SV, Mansfield JF, Schwank JW. In-situ elevated temperature imaging of thin films with a microfabricated hot stage for scanning probe microscopes. Applied Surface Science. 1999;141:119-28.

[23] Trawick ML, Angelescu DE, Chaikin PM, Valenti MJ, Register RA. A replaceable, low thermal mass hot stage for scanning probe microscopy. Review of Scientific Instruments. 2003;74:1390-2.

[24] Broekmaat J, Brinkman A, Blank DHA, Rijnders G. High temperature surface imaging using atomic force microscopy. Applied Physics Letters. 2008;92:-.

[25] Allers W, Schwarz A, Schwarz UD, Wiesendanger R. A scanning force microscope with atomic resolution in ultrahigh vacuum and at low temperatures. Review of Scientific Instruments. 1998;69:221-5.

[26] Bluhm H, Pan SH, Xu L, Inoue T, Ogletree DF, Salmeron M. Scanning force microscope and vacuum chamber for the study of ice films: Design and first results. Review of Scientific Instruments. 1998;69:1781-4.

[27] Hansen KV, Wu Y, Jacobsen T, Mogensen MB, Theil Kuhn L. Improved controlled atmosphere high temperature scanning probe microscope. Review of Scientific Instruments. 2013;84:-.

[28] Huang X, Nohava J, Zhang B, Ramirez AG. Nanoindentation of NiTi shape memory thin films at elevated temperatures. International Journal of Smart and Nano Materials. 2011;2:3949.

[29] Wheeler JM, Raghavan R, Michler J. In situ SEM indentation of a Zr-based bulk metallic glass at elevated temperatures. Materials Science and Engineering: A. 2011;528:8750-6.

[30] Wheeler JM, Niederberger C, Tessarek C, Christiansen S, Michler J. Extraction of plasticity parameters of $\mathrm{GaN}$ with high temperature, in situ micro-compression. International Journal of Plasticity. 2013;40:140-51.

[31] Rajulapati KV, Biener MM, Biener J, Hodge AM. Temperature dependence of the plastic flow behavior of tantalum. Philos Mag Lett. 2009;90:35-42.

[32] Korte S, Clegg WJ. Micropillar compression of ceramics at elevated temperatures. Scripta Materialia. 2009;60:807-10.

[33] Wheeler JM, Brodard P, Michler J. Elevated temperature, in situ indentation with calibrated contact temperatures. Philos Mag. 2012;92:3128-41.

[34] Korte S, Barnard JS, Stearn RJ, Clegg WJ. Deformation of silicon - Insights from microcompression testing at $25-500^{\circ} \mathrm{C}$. International Journal of Plasticity. 2011;27:1853-66.

[35] Zaitsev AM. Optical properties of diamond: a data handbook: Springer; 2001.

[36] Weihs T, Pethica J. Monitoring time-dependent deformation in small volumes. MRS Proceedings: Cambridge Univ Press; 1991. p. 325.

[37] Pharr GM, Strader JH, Oliver WC. Critical issues in making small-depth mechanical property measurements by nanoindentation with continuous stiffness measurement. Journal of Materials Research. 2009;24:653-66.

[38] Syed Asif SA, Pethica JB. Nanoindentation creep of single-crystal tungsten and gallium arsenide. Philosophical Magazine A. 1997;76:1105-18.

[39] Maier V, Merle B, Göken M, Durst K. An improved long-term nanoindentation creep testing approach for studying the local deformation processes in nanocrystalline metals at room and elevated temperatures. Journal of Materials Research. 2013;28:1177-88.

[40] Cheng I, Garcia-Sanchez E, Hodge A. Note: A method for minimizing oxide formation during elevated temperature nanoindentation. Review of Scientific Instruments. 2014;85:096106. 
[41] Draper JW. On the production of Light by Heat. London and Edinburgh Philosophical Magazine and Journal of Science. 1847;30:345-59.

[42] Pfetzing-Micklich J, Ghisleni R, Simon T, Somsen C, Michler J, Eggeler G. Orientation dependence of stress-induced phase transformation and dislocation plasticity in NiTi shape memory alloys on the micro scale. Materials Science and Engineering: A. 2012;538:265-71.

[43] Wheeler JM, Raghavan R, Michler J. Temperature invariant flow stress during microcompression of a Zr-based bulk metallic glass. Scripta Materialia. 2012;67:125-8.

[44] Schwaiger R, Weber M, Moser B, Gumbsch P, Kraft O. Mechanical assessment of ultrafine-grained nickel by microcompression experiment and finite element simulation. Journal of Materials Research. 2012;27:266-77.

[45] Di Gioacchino F, Clegg WJ. Mapping deformation in small-scale testing. Acta Materialia. 2014;78:103-13.

lbins i . nstrumentierte indringpr fung bei oc htemperatur $\mathrm{fr}$ die Charakterisierung bestrahlter Materialien: Karlsruhe, Karlsruher Institut f r Technologie (KIT), Diss., 2013; 2013.

[47] Heinz W, Pippan R, Dehm G. Investigation of the fatigue behavior of Al thin films with different microstructure. Materials Science and Engineering: A. 2010;527:7757-63.

[48] Heinz W, Dehm G. Grain resolved orientation changes and texture evolution in a thermally strained Al film on Si substrate. Surface and Coatings Technology. 2011;206:18504.

[49] Heinz W, Robl W, Dehm G. Influence of initial Microstructure on Thermo-mechanical Fatigue Behaviour of Cu Films on Substrates. Microelectronic Engineering. 2014; in press.

[50] Weimer AW. Carbide, nitride and boride materials synthesis and processing: Springer; 1997.

[51] Pierson HO. Handbook of carbon, graphite, diamond and fullerenes: Noyes publications; 1993.

[52] Slack GA. Nonmetallic crystals with high thermal conductivity. Journal of Physics and Chemistry of Solids. 1973;34:321-35.

[53] Goto T, Anderson OL, Ohno I, Yamamoto S. Elastic constants of corundum up to 1825 K. Journal of Geophysical Research. 1989;94:7588.

5 Reeber RR, Wang K. Thermophysical Properties of $\alpha$-Tungsten Carbide. Journal of the American Ceramic Society. 1999;82:129-35.

[55] Reeber RR, Wang K. Thermal expansion, molar volume and specific heat of diamond from 0 to 3000k. Journal of Electronic Materials. 1996;25:63-7.

[56] Slack GA, Bartram SF. Thermal expansion of some diamondlike crystals. Journal of Applied Physics. 1975;46:89-98.

[57] Thévenot F. Boron carbide-A comprehensive review. Journal of the European Ceramic Society. 1990;6:205-25.

[58] Wachtman JB, Scuderi TG, Cleek GW. Linear Thermal Expansion of Aluminum Oxide and Thorium Oxide from $100^{\circ}$ to $1100^{\circ} \mathrm{K}$. Journal of the American Ceramic Society. 1962;45:319-23.

[59] Caillard D, Martin JL. Thermally Activated Mechanisms in Crystal Plasticity: Elsevier Science; 2003.

[60] Wheeler JM, Maier V, Durst K, Göken M, Michler J. Activation parameters for deformation of ultrafine-grained aluminium as determined by indentation strain rate jumps at elevated temperature. Materials Science and Engineering: A. 2013;585:108-13. 
[61] Mohanty G, Wheeler JM, Raghavan R, Wehrs J, Hasegawa M, Mischler S, et al. Elevated temperature, strain rate jump microcompression of nanocrystalline nickel. Philos Mag. 2014:1-18.

[62] Chu S, Li J. Impression creep; a new creep test. J Mater Sci. 1977;12:2200-8.

[63] Dean J, Campbell J, Aldrich-Smith G, Clyne T. critical assessment of the -stable indenter velocity" method for obtaining the creep stress exponent from indentation data. c ta Materialia. 2014;80:56-66.

[64] Choi I-C, Kim Y-J, Seok M-Y, Yoo B-G, Kim J-Y, Wang Y, et al. Nanoscale room temperature creep of nanocrystalline nickel pillars at low stresses. International Journal of Plasticity. 2013;41:53-64.

[65] Afrin N, Ngan A. Creep of micron-sized $\mathrm{Ni}<\mathrm{sub}>3</$ sub $>$ Al columns. Scripta materialia. 2006;54:7-12.

$\mathrm{R}$ aumur R- $\mathrm{d}$. art de convertir le fer forg en acier 1 art $\mathrm{d}$ adoucir le fer fondu, ou de faire des ouvrages de fer fondu aussi finis que de fer forg . Paris: Chez M. Brunet; 1722.

[67] Atkins AG, Tabor D. Hardness and Deformation Properties of Solids at Very High Temperatures. Proceedings of the Royal Society A: Mathematical, Physical and Engineering Sciences. 1966;292:441-59.

[68] Chen J, Bell GA, Dong H, Smith JF, Beake BD. A study of low temperature mechanical properties and creep behaviour of polypropylene using a new sub-ambient temperature nanoindentation test platform. Journal of Physics D: Applied Physics. 2010;43:425404.

[69] Lee S-W, Meza L, Greer JR. Cryogenic nanoindentation size effect in [ [ $\left.\begin{array}{lll}0 & 0 & 1\end{array}\right]$-oriented face-centered cubic and body-centered cubic single crystals. Applied Physics Letters. 2013;103:-.

[70] Lee S-W, Cheng Y, Ryu I, Greer J. Cold-temperature deformation of nano-sized tungsten and niobium as revealed by in-situ nano-mechanical experiments. Sci China Technol Sci. 2014;57:652-62.

[71] Lupinacci A, Kacher J, Eilenberg A, Shapiro AA, Hosemann P, Minor AM. Cryogenic in situ microcompression testing of Sn. Acta Materialia. 2014;78:56-64. 